\title{
HIỆU QUẢ THUỐC SULPIRIDE TRONG CẢI THIỆN CHẤT LƯợNG CUộC SỐNG Ở BỆNH NHẬN HộI CHỨNG RUộTT KÍCH THÍCH
}

\section{TÓM TẮT.}

Đặt vấn đề: Hội chứng ruột kích thích (IBS) là một bệnh lý với các triệu chứng đường tiêu hóa như đau bụng, chướng bụng, đây hơi, ảnh hưởng nhiều đến chất lượng cuôc sống (CLCS) của bênh nhân (BN). Mục tiêu: Khảo sát hiệu quả điều trị của thuốc sulpiride trong cải thiên chất lượng cuộc sống ở bệnh nhận hội chứng ruột kích thích. Đối tượng và phương pháp nghiền cứu: Nghiên cứu cắt ngang mô tả thực hiện trên những BN IBS được bác sĩ chẩn đoán bằng tiêu chuẩn ROME III tai phòng khám Tiêu hoá, bệnh viện Đại học Y Dược TP. Hồ Chí Minh từ 01/06/2018 - 01/02/2019, có hoặc không sử dung sulpiride. Thu thập số liệu về đặc điểm nền của bệnh nhân, điểm CLCS được thu thập dựa trên bộ câu hỏi IBS-QoL phiên bản tiếng Việt đã được dịch thuật và thẩm định cho toàn bộ đối tượng tham gia nghiên cứu tại thời điểm ban đầu và sau 8 tuân theo dõi. Kết quả: Sau 8 tuần theo dõi, $246 \mathrm{BN}$ hoàn thành nghiên cứu, trong đó $120 \mathrm{BN}$ nhóm điều trị có sulpiride và 126 BN nhóm điều trị không có sulpiride, tỷ lệ nữ/nam là 1,4/1. Sau 8 tuần theo dỗi, kết quả điểm CLCS tổng thể và các điểm CLCS ở các khía cạnh đặc điểm khó chịu, lo lắng sức khỏe, phản ứng xã hội, mối quan hệ cao hơn có ý nghĩa thống kê so với nhóm không sulpiride $(p<0,001)$. Khi đánh giá độ thay đổi điểm CLCS, độ thay đổi điểm CLCS tổng thể và các khía canh khó chiu, cản trở hoat đông, hình thể, lo lắng sức khỏe, phản ứng xã hội, mổi quan hệ ở nhóm có sulpiride cũng cao hơn có ý nghĩa thống kê so với nhóm không dùng sulpiride, ulpuride $(p<0,05)$. Kết luân: Sử dụng thuốc sulpiride điều trị BN IBS giúp cải thiện CLCS tổng thể, thay đổi ở các đặc điểm khó chịu, cản trở hoạt động, hình thể, lo lắng sức khỏe, phản ứng xã hội, mối quan hệ.

Tư khoá: Sulpiride, hội chứng ruột kích thích, chất lượng cuộc sống.

\section{SUMMARY \\ THE EFFECT OF SULPIRIDE IN IMPROVING QUALITY OF LIFE OF PATIENTS WITH IRRITABLE BOWEL SYNDROME}

Background: Irritable bowel syndrome (IBS) is a chronic gastrointestinal disease associated with bowel dysfunction, which can significantly impact the quality of life (QoL) of patients. Objectives: To investigate the effect of sulpiride in improving quality in patients with IBS by ROME III criteria at University Medical

\footnotetext{
${ }^{1}$ Đại học Y Dược Thành phố Hồ Chí Minh ${ }^{2}$ Bềnh viện Chơ Rẫy, Thành phố Hồ Chí Minh Chịu trách nhiệm chính: Võ Duy Thông Email: duythong@ump.edu.vn

Ngày nhận bài: 2.3.2021

Ngày phản biên khoa hoc: 16.4.2021

Ngày duyệt bài: 27.4.2021
}

\section{Võ Duy Thông ${ }^{1,2}$, Nguyễn Ngọc Phúc ${ }^{1}$}

Center. Methods: We conducted a cross-sectional study in patients diagnosed with IBS at the Gastroenterology clinic of University Medical Center from $01^{\text {st }}$ June, 2018 to $1^{\text {st }}$ February, 2019, indicated with or without sulpiride. The data of patient informations were collected, the QoL of patients was accessed based on validated Vietnamese version IBSQoL questionnaire for all participants at the baseline. and after 8 weeks of follow-up. Results: After 8 weeks of follow-up, 246 patients completed the study, of which 120 patients used sulpiride and 126 patients did not use sulpiride, the female / male ratio was 1.4/1. After 8 weeks of follow-up, the overall IBS-QoL score and the domains of IBS-QoL in irritability, health anxiety, social response, and relationship in sulpiride group were statistically significantly higher than those in the non-sulpiride group. $(p<0.001)$. The change in IBS-QoL score, the change in domain of discomfort, obstruction of performance, fitness, health anxiety, social reactions, and relationship in the sulpiride group were also higher than these in non-sulpiride group ( $p$ $<0.05$ ). Conclusion: The use of sulpiride in the treatment of IBS patients improved overall QoL score, especially changes in the domain of uncomfortable characteristics, impeded performance, physical fitness, health anxiety, social reactions, relationships.

Keywords: Sulpiride, irritable bowel syndrome, quality of life.

\section{I. ĐĂT VẤN ĐỀ}

Hội chứng ruột kích thích (IBS) là một bệnh lý với các triệu chứng đường tiêu hóa như đau bụng, chướng bụng, đầy hơi... Mặc dù IBS khá phổ biến nhưng việc chẩn đoán và điều trị IBS tương đối khó khăn. IBS tuy không dẫn đển tử vong nhưng ảnh hưởng nhiều đến sinh hoạt hàng ngày, lao động, học tập và chất lượng cuộc sống (CLCS) của bệnh nhân (BN). Nghiên cứu về IBS là đề tài khá phổ biến trên thế giới, qua đó, tác giả quan tâm nhiều đến các yếu tố tác động đến IBS; lo âu, trầm cảm và CLCS của BN IBS cũng như các biện pháp giúp BN cải thiện triệu chứng IBS [1], [2]. Tuy nhiên tại Việt Nam, nghiên cứu về IBS không nhiều, kiến thức của BN về các thuốc điều trị triệu chứng IBS vẫn còn hạn chế. Trong khi ảnh hưởng của IBS đến đời sống hàng ngày của $B N$ là rất lớn. Do vậy, cần có nhiều nghiên cứu hơn nữa về hội chứng này. Mặt khác, khi đời sống kinh tế xã hội đang ngày càng phát triển như hiện nay, CLCS sẽ ngày càng trở thành vấn đề được quan tâm do liên quan mật thiết đến tình trạng sức khỏe của mỗi cá nhân. Một số nghiên cứu cho thấy IBS làm 
giảm CLCS [1]. BN IBS được điều trị bằng cách làm giảm các triệu chứng riêng lẻ của IBS như đầy hơi, đau bụng, tiêu chảy và táo bón. Bệnh IBS thường liên quan đến lo lắng, trầm cảm và rối loạn tâm trạng. Do đó, thuốc chống trầm cảm liều thấp có hoặc không có thuốc chống co thắt đã được sử dụng để điều trị [3]. Sulpiride là một dẫn xuất benzamid được sử dụng để chống loạn thần, chống trầm cảm và chống nôn. Cơ chế tác động của sulpiride trên BN IBS chưa được biết rõ, cơ chế được đề xuất là sulpiride đối kháng thụ thể dopamin trung ương và ngoại biên, làm giảm nhu động ruột và được sử dụng trong điều trị IBS. Sulpiride làm giảm các triệu chứng rối loạn vận động kết tràng sau ăn (đau bụng, tiêu chảy), liều dùng cho đối tượng nghiên cứu là $100 \mathrm{mg}$ sulpiride tiêm bắp [3]. Nghiên cứu về hiệu quả của sulpiride trên BN IBS vẫn còn hạn chế, nhưng hiện nay tại một số bệnh viện trền địa bàn TP. Hồ Chí Minh, sulpiride được chỉ định sử dụng nhiều trên BN IBS. Do đó, mục tiêu nghiên cứu nhằm khảo sát hiệu quả điều trị của thuốc sulpiride trong cải thiện chất lượng cuộc sống ở bệnh nhận hội chứng ruột kích thích.

\section{II. ĐỐI TƯỢNG VÀ PHƯƠNG PHÁP NGHIÊN CỨU}

Phương pháp nghiên cứu: Nghiên cứu đoàn hệ tiến cứu

Đối tượng nghiên cứu: BN ngoại trú được chẩn đoán IBS, đến khám và điều trị tại phòng khám tiêu hóa, bệnh viện Đại học Y Dược Thành phố. Hồ Chí Minh, thoả mãn các tiêu chuẩn sau:

Tiêu chuẩn chọn mẫu: BN được chẩn đoán IBS theo tiêu chuẩn ROME III. BN đủ 18 tuổi trở lên đến khám tại phòng khám tiêu hóa Bệnh viện Đại học Y Dược TP. Hồ Chí Minh từ ngày $01 / 06 / 2018-01 / 02 / 2019$ và $B N$ đồng ý tham gia nghiên cứu.

Tiêu chuẩn loại trừ: Hồ sơ bệnh án không đủ thông tin nghiển cứu, bệnh nhân có tiền sử phẫu thuâat đại tràng

Cỡ mẫu: Tất cả bệnh nhân thoả tiêu chuẩn chọn mẫu và không có tiêu chuẩn loại trừ.

Đặc điểm nền của bệnh nhân

\begin{tabular}{|c|c|c|c|c|}
\hline \multirow[b]{2}{*}{ Đặc điểm } & \multirow{2}{*}{$\begin{array}{c}\text { Tổng } \\
(n=246) \\
{[n(\%)]}\end{array}$} & \multicolumn{2}{|c|}{ Phân nhóm [n (\%)] } & \multirow[b]{2}{*}{ Giá trị p } \\
\hline & & $\begin{array}{c}\text { Có sulpiride } \\
(\mathrm{n}=120)\end{array}$ & $\begin{array}{c}\text { Không sulpiride } \\
(\mathrm{n}=126)\end{array}$ & \\
\hline $\begin{array}{ll}\text { Giới tính: } & \begin{array}{l}N a m \\
N u ̛ ̃\end{array} \\
& \end{array}$ & $\begin{array}{l}103(41,9) \\
143(58,1)\end{array}$ & $\begin{array}{l}51(42,5) \\
69(57,5)\end{array}$ & $\begin{array}{l}52(41,3) \\
74(58,7)\end{array}$ & 0,701 \\
\hline $\begin{array}{r}\text { Nhóm tuối: } \leq 30 \text { tuối } \\
31-60 \text { tuổi } \\
\text { Trên } 60 \text { tuổi }\end{array}$ & $\begin{array}{c}52(21,1) \\
171(69,6) \\
23(9,3)\end{array}$ & $\begin{array}{c}26(21,7) \\
84(70,0) \\
10(8,3)\end{array}$ & $\begin{array}{l}26(20,6) \\
87(69,0) \\
13(10,3)\end{array}$ & 0,323 \\
\hline Trình độ học vấn & & & & 0,695 \\
\hline
\end{tabular}

Các bước tiến hành và phân tích số liệu. Số liệu được thu thập tại phòng khám tiêu hoá, Bệnh viện Đại học Y Dược TP. Hồ Chí Minh và thông qua phỏng vấn trực tiếp $B N$ tại thời điểm nhân vào nghiên cứu và theo dõi sau mỗi đợt tái khám. BN được chia ngẫu nhiên thành hai nhóm: Nhóm điêu trị có sulpiride (có sulpiride) và nhóm điều trị không có sulpiride (không sulpiride).

Dữ liệu về đặc điểm nền của bệnh nhân (tuổi, giới, nghề nghiệp, phân loại IBS, trình độ học vấn, tình trạng hôn nhân), lối sống, thói quen sinh hoạt của $B N$ (căng thẳng, hút thuốc lá, uống rượu, sử dụng cà phê, sử dụng đồ uống có gas, vận động) được dược sĩ thu thập vào thời điểm bắt đầu nghiển cứu. Điểm CLCS được thu thập dựa trên bộ câu hỏi IBS-QoL phiên bản tiểng Việt đã được dịch thuật và thẩm định [4] cho toàn bộ đối tượng tham gia nghiên cứu tại thời điểm ban đầu và sau 8 tuần theo dõi. Điểm IBS-QoL cao hơn thể hiện CLCS cao hơn.

Phân tích dữ liệu: Dữ liệu được xử lý và trình bày bằng phần mềm SPSS 20.0. Dữ liệu được trình bày bằng trung bình $\pm S D$ với biến liên tục và tỷ lệ với biến phân loại. So sánh các giá trị trung bình điểm CLCS giữa nhóm sử dụng phép kiểm T-test hoăc Mann Whitney. Sử dụng hồi quy tuyến tính đa biến để tìm xác định mối liên quan giữa các yếu tố đến thay đổi điểm CLCS. Giá trị $p<0,05$ được xem là có ý nghĩa thống kê.

Vấn đề đạo đức: Quy trình nghiên cứu được Hội đồng nghiên cứu khoa học của Đại học Y Dược TP. Hồ Chí Minh thông qua và được tiến hành đảm bảo tuân thủ các nguyên tắc đạo đức trong nghiên cứu Y Học.

\section{KẾT QUẢ NGHIÊN CỨU}

Tổng cộng có 289 BN thoả tiêu chuẩn chọn mẫu đồng ý tham gia vào nghiên cứu được phẩn vào 2 nhóm: $137 \mathrm{BN}$ nhóm có sulpiride và 152 BN nhóm không sulpiride. Sau 8 tuần theo dõi, $246 \mathrm{BN}$ hoàn thành nghiên cứu, trong đó $120 \mathrm{BN}$ nhóm điều trị có sulpiride và 126 BN nhóm điều trị không có sulpiride. 


\begin{tabular}{|c|c|c|c|c|}
\hline Chưa tốt nghiệp phố thông & $129(52,4)$ & $64(53,3)$ & $65(51,6)$ & \\
Tốt nghiệp trung hơc phổ thông & $30(12,2)$ & $14(11,7)$ & $16(12,7)$ & \\
Cao đăng/đại học/sau đại học & $87(35,4)$ & $42(35,0)$ & $45(35,7)$ & \\
\hline Nghề nghiệp: Sinh viên & $10(41,1)$ & $5(4,2)$ & $5(4,0)$ & \\
Nông dân & $37(15,0)$ & $19(15,8)$ & $18(14,3)$ & \\
Công nhân & $30(12,2)$ & $15(12,5)$ & 15 & \multirow{2}{*}{0,031} \\
Nhân viên văn phòng & $64(26,0)$ & $33(27,5)$ & 31 & \\
Kinh doanh & $42(17,1)$ & $20(16,7)$ & 22 & \\
Khác & $63(25,6)$ & $28(23,3)$ & 35 & \\
Tình trạng hôn nhân: Độc thân & $43(17,5)$ & $22(18,3)$ & $21(16,7)$ & \multirow{2}{*}{0,832} \\
Có gia đình & $203(82,5)$ & $98(81,7)$ & $105(83,3)$ & \\
\hline Loại IBS: IBS-D & $170(69,1)$ & $86(71,7)$ & $84(66,7)$ & \multirow{2}{*}{0,367} \\
IBS-C & $21(8,5)$ & $7(5,8)$ & $14(11,1)$ & \\
IBS-M & $55(22,4)$ & $27(22,5)$ & $28(22,2)$ & \\
\hline
\end{tabular}

*Nghề nghiệp/ khác gồm: nội trợ, hưu trí, công việc thời vụ, lái xe

*Chưa tốt nghiệp phổ thông: trình độ học vấn của bệnh nhân từ lớp 12 trở xuống chưa thi tốt nghiệp phổ thông. Tốt nghiệp trung học phổ thông: bệnh nhân tốt nghiệp trung học phổ thông và tham gia vào lực lượng lao động

*IBS-D: IBS thể tiêu chảy; IBS-C: IBS thể táo bón; IBS-M: IBS thể hỗn hợp

Điểm chât lượng cuộc sống sau 8 tuàn theo dôi

Qua kết quả phân tích nhận thấy, tỷ lê $B N$ IBS có lo lắng, căng thẳng là $63,8 \%$. Tất cả BN nam điều hút thuốc là và tỷ lệ BN hút thuốc lá là $8,7 \%$. Không có sự khác biệt có ý nghĩa thống kê giữa hai nhóm về tình trạng căng thẳng, uống rượu, cà phê, vận động và hút thuốc lá. Phân tích về điểm CLCS ở 2 nhóm có sulpiride và không có sulpiride, kết quả cho thấy không có sự khác biệt có ý nghĩa thống kê đối với điểm CLCS tổng thể và điểm CLCS các khía cạnh của cả 2 nhóm ở thời điểm ban đầu ( $p>0,05)$ (Bảng 2).

Bảng 2. Đặc điểm chất lượng cuộc sống ban đầu giữa hai nhóm

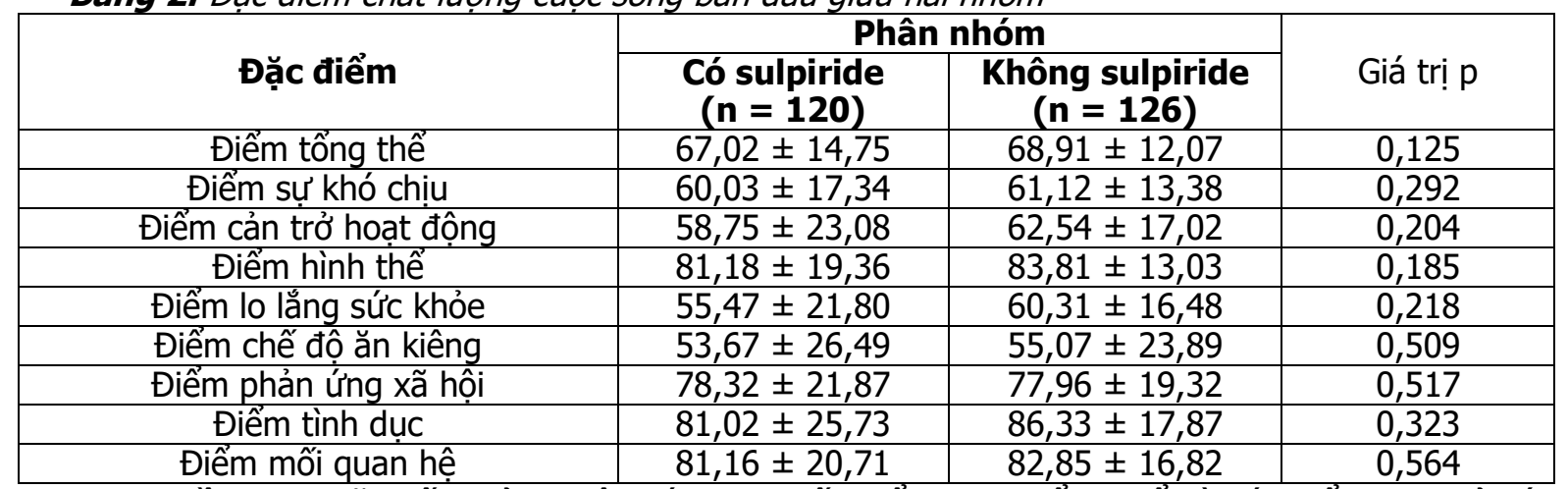

Sau 8 tuần theo dõi, kết quả nghiên cứu cho thấy điểm CLCS tổng thể và các điểm CLCS ở các khía cạnh đặc điểm khó chịu, lo lắng sức khỏe, phản ứng xã hội, mối quan hệ cao hơn có ý nghĩa thống kê so với nhóm không sulpiride $(p<0,001)$. Khi đánh giá độ thay đổi điểm $C L C S$, kết quả cho thây độ thay đổi điểm CLCS tổng thể và các khía cạnh khó chịu, cản trở hoạt động, hình thể, lo lắng sức khỏe, phản ứng xã hội, mối quan hệ ở nhóm có sulpiride cũng cao hơn có ý nghĩa thống kê so với nhóm không sulpiride $(p<0,05)$ (Bảng 3 ).

Bảng 3. Điểm chất lượng cuộc sống sau 8 tuần theo dôi

\begin{tabular}{|c|c|c|c|}
\hline \multirow{2}{*}{ Điểm CLCS sau 8 tuân theo dõi } & \multicolumn{2}{|c|}{ Phân nhóm } & \multirow{2}{*}{ Giá trị $\mathrm{p}$} \\
\cline { 2 - 3 } & $\begin{array}{c}\text { Có sulpiride } \\
(\mathbf{n = 1 2 0 )}\end{array}$ & $\begin{array}{c}\text { Không sulpiride } \\
(\mathbf{n = 1 2 6})\end{array}$ & \\
\hline Điểm trung bình CLCS & & & 0,004 \\
\hline Điểm tổng thể & $86,51 \pm 8,93$ & $82,87 \pm 7,56$ & 0,005 \\
\hline Điếm sự khó chịu & $88,23 \pm 13,81$ & $81,02 \pm 7,06$ & 0,903 \\
\hline Điếm cản trở hoạt động & $79,90 \pm 15,21$ & $79,06 \pm 12,15$ & 0,492 \\
\hline Điểm hình thế & $92,56 \pm 11,19$ & $91,85 \pm 9,88$ & 0 \\
\hline
\end{tabular}


TAP CHÍ Y HOC VIÊT NAM TÂP 502 - THÁNG 5 - SỐ 1 - 2021

\begin{tabular}{|c|c|c|c|}
\hline Điểm lo lắng sức khỏe & $88,92 \pm 16,24$ & $75,89 \pm 14,54$ & $<0,001$ \\
\hline Điểm chễ độ ăn kiêng & $62,51 \pm 24,01$ & $63,17 \pm 18,63$ & 0,918 \\
\hline Điếm phản ứng xã hội & $92,17 \pm 13,90$ & $82,32 \pm 14,08$ & $<0,001$ \\
\hline Điểm tình dục & $86,91 \pm 20,75$ & $88,04 \pm 16,18$ & 0,712 \\
\hline Điểm mối quan hệ & $95,20 \pm 11,15$ & $84,72 \pm 14,56$ & $<0,001$ \\
\hline \multicolumn{4}{|l|}{ Sự thay đối $(\Delta)$ điếm CLCS } \\
\hline$\Delta$ tống thế & $20,89 \pm 11,90$ & $12,78 \pm 12,68$ & $<0,001$ \\
\hline$\Delta$ sự khó chịu & $29,51 \pm 16,38$ & $25,04 \pm 13,93$ & 0,006 \\
\hline$\Delta$ cản trở hoạt động & $22,11 \pm 18,13$ & $16,18 \pm 18,32$ & 0,031 \\
\hline$\Delta$ hình thế & $13,17 \pm 13,52$ & $8,92 \pm 14,51$ & 0,047 \\
\hline$\Delta$ lo lắng sức khỏe & $33,64 \pm 22,78$ & $15,20 \pm 19,37$ & $<0,001$ \\
\hline$\Delta$ chế độ ăn kiêng & $10,04 \pm 23,59$ & $10,71 \pm 28,39$ & 0,812 \\
\hline$\Delta$ phản ứng xã hội & $15,50 \pm 18,91$ & $7,73 \pm 21,80$ & 0,003 \\
\hline$\Delta$ tình dục & $8,21 \pm 17,46$ & $3,08 \pm 24,65$ & 0,089 \\
\hline$\Delta$ mối quan hệ & $16,12 \pm 16,45$ & $2,19 \pm 22,04$ & $<0,001$ \\
\hline
\end{tabular}

$\Delta:$ Sự thay đổi điểm so với giá trị ban đâu

Khi phân tích hồi quy tuyến tính đa biến, kết quả cho thấy có mối liên quan giữa độ thay đổi từng điểm CLCS và hiệu quả của sulpiride giúp cải thiện CLCS ở BN IBS, nghiên cứu sau 8 tuần theo dõi.

\section{BÀN LUÂ̂N}

Kết quả nghiên cứu cho thấy thuốc an thần kinh là sulpiride với 120/246 BN IBS được chỉ định sử dụng, chiếm tỷ lệ $48,8 \%$. Sulpiride là một dẫn xuất benzamid được sử dụng để chống loạn thần, chống trầm cảm và chống nôn. Cơ chế tác động của sulpiride trên BN IBS chưa được biết rõ, cơ chế được đề xuất là sulpiride đối kháng thụ thể dopamin trung ương và ngoại biên, làm giảm nhu động ruột và được sử dụng trong điều trị IBS. Sulpiride làm giảm các triệu chứng rối loạn vận động kết tràng sau ăn (đau bụng, tiêu chảy) [3].

Sau 8 tuần theo dõi, có sự cải thiện đáng kể về CLCS ở nhóm có sulpiride so với nhóm không sulpiride. CLCS được cải thiện ở các khía cạnh: sự khó chịu, cản trở hoạt động, hình thể, lo lắng sức khoẻ, phản ứng xã̃ hội, mối quan hệ. Kết quả phân tích hồi quy tuyển tính đa biến khẳng định lại mối quan hệ tích cực giữa hiệu quả sulpiride và sự cải thiện CLCS ở BN IBS. Kết quả nghiên cứu là cơ sở đầu tiên cho thấy hiệu quả của sulpiride trong việc cải thiện CLCS của BN IBS. Kết quả nghiên cứu của Jarrett cho thấy có sự cải thiện đáng kể ở triệu chứng IBS và cả điểm CLCS ở nhóm có sulpiride và nhóm không sulpiride $(p<0,001)$ [5]. Nghiên cứu của Schneider ghi nhận có sự cải thiện CLCS dần trong 3 tháng có ý nghĩa thống kề $(p<0,05)$ [6]. Các nghiên cứu cho thấy việc dùng thuốc cải thiện tình trạng rối loạn lo âu ở BN mắc IBS giúp cải thiện CLCS liên quan đến sức khỏe, điểm phản ứng xã hội và cải thiện điểm mối quan hệ.

Nghiên cứu cho kết quả tương đồng với nhiều nghiên cứu trong và ngoài nước về tỷ lệ mắc IBS-
D cao, với $69,1 \%$. Trong nghiên cứu của Dorn S.D [7], thời gian mắc IBS trung bình là 6,3 năm (dao động từ 3 tháng đến 23 năm). Thời gian mắc IBS kéo dài nhiêu năm, các triệu chứng xảy ra ô ạt làm $\mathrm{BN}$ mệt mỏi, khó chịu, ảnh hưởng đến sinh hoạt, cuộc sống hàng ngày Với cơ chế tác động của Sulupide ngoài làm giảm triệu chứng rối loạn vận động như đau bụng và tiêu chảy, thuốc còn cải thiện tình trang lo âu của bệnh nhân, từ đó giúp cải thiện tổng thể CLCS ở nhóm có sulpiride so với nhóm không sulpiride.

Trong nghiên cứu của chúng tôi, liêu dùng sulpiride tương tự nghiên cứu của Dorn S.D (50mg x 2 lần/ngày), sau 8 tuần theo dõi, kết qủa cho thấy điểm CLCS tổng thể thay đổi đáng kể so với nhóm không sulpiride, đặc biệt ở đặc điểm khó chịu, lo lắng sức khoẻ, phản ứng xã hội và các mối quan hệ. Đồng thời, độ thay đổi điểm CLCS cũng thay đổi nhiều so với với nhóm không sulpiride. Tuy nhiên, về thời gian điều trị hiện vẫn chưa thống nhất ở một số nghiên cứu cũng như ở các hướng dẫn điều trị. Trong hướng dẫn thực hành trên BN IBS năm 2017 của hiệp hội tiêu hoá Hàn Quốc cũng khuyến cáo sử dụng thuốc điều trị IBS trong vòng 4 tuần, sau đó đánh gía lại tình trạng $\mathrm{BN}$ và xem xét tiếp tục sử dụng thuốc.

\section{KẾT LUẬN}

Sử dụng thuốc sulpiride điều trị BN IBS giúp cải thiên CLCS tổng thể, đặc điệc thay đổi ở các đặc điểm khó chịu, cản trở hoạt động, hình thể, lo lắng sức khỏe, phản ứng xã hội, mối quan hệ. Nghiên cứu được tiến hành tại một trung tâm, do vậy việc cần khảo sát sử dụng thuốc sulpiride 
tại các bệnh viện để mở rộng nghiên cứu đánh giá hiệu quả của các thuốc.

\section{TÀI LIÊU THAM KHẢO}

1. Canavan C. et al. The epidemiology of irritable bowel syndrome. Clinical epidemiology. 2014. 6:71.

2. Võ Thị Thuý Kiêu, Bùi Thi Hương Quỳnh, Võ Duy Thông. Khảo sát viêc điêuu trị hôi chứng ruôt kích thích tại bệnh viện Nhân Dân Gia Định. Tạp chí Y hoc TP. Hồ Chí Minh. 2015. 19: 760-765.

3. Agarwal $\mathbf{N}$, Spiegel BM. The effect of irritable bowel syndrome on health-related quality of life and health care expenditures. Gastroenterology Clinics. 2011; 40(1):11-19

4. Doan Phan Ngoc Thao, Nguyen Ngoc Phuc, Vo Duy Thong, Bui Thi Huong Quynh. Investigation of quality of life and factors related to quality of life of patients with irritable bowel syndrome. Vietnam Journal of Medicine and Pharmacy. 2018. 23(2):227-233.

5. Jarrett ME, Cain KC, Burr RL, et al. Comprehensive self-management for irritable bowel syndrome: Randomized trial of in-person versus combined in-person and telephone sessions. The American Journal of Gastroenterology. 2009. 104(12):3004

6. Schneider A, Rosenberger S, Bobardt J. Selfhelp guidebook improved quality of life for patients with irritable bowel syndrome. PloS One. 2017. 12(7): e0181764.

7. Dorn SD, Palsson OS, Woldeghebriel $M$, et al. Development and pilot testing of an integrated, web-based self-management program for irritable bowel syndrome (IBS). Neurogastroenterology \& Motility. 2015; 27(1):128-134.

\section{CHI PHÍ TRỰC TIẾP ĐIỀU TRI UNG THƯ GAN TẠI VIỆT NAM, NĂM 2019}

\section{TÓM TẮT}

Mục tiêu: Nghiên cứu được thực hiện nhằm đo lường chi phí trực tiếp điều trị ung thư gan tại Việt Nam năm 2019. Phương pháp nghiên cứu: Nghiển cứu mô tả cắt ngang, dựa trên hồi cứu số liệu từ hồ sơ thanh toán khi ra viện và phỏng vấn 90 người bệnh ung thư gan hoàn thành đợt điều trị trong thời gian thu thâp số liệu của nghiên cứu, từ tháng 12/2019 đến tháng 6/2020 tại bệnh viện K Trung Ương. Kết quả và kết luân: Nghiên cứu cho thấy, trong đợt điều trị hiện tại, tổng chi phí trực tiếp vào khoảng 47.305.000 VNE் với chi phí thấp nhất là 12.957.000 VNĐ và chi phí cao nhất là 111.680.000 VNĐ. Đối với tổng chi phí trong năm 2019, tổng chi phí trực tiếp trung bình lên đến tổng chi phí trực tiếp vào khoảng 250.857.000 VNĐ với chi phí thấp nhất là 31.288.000 VNĐ và chi phí cao nhất là 1.291.727.000 VNĐ. Trong các nhóm chi phí, chi phí tiền túi hộ gia đình đều chiếm tỷ trong lớn hơn. Việt Nam

Tư khoá: Chi phí điều trị trực tiếp, ung thư gan,

\section{SUMMARY}

\section{DIRECT COST OF LIVER CANCER} TREATMENT IN VIETNAM, 2019

Objective: To measure the direct cost of liver cancer treatment in Vietnam in 2019. Methods: Cross-sectional descriptive study, based on

*Trường Đại học Y tế Công Cộng

Chịu trách nhiệm chính: Nguyễn Quỳnh Anh

Email: nqa@huph.edu.vn

Ngày nhận bài: 4.3.2021

Ngày phản biện khoa học: 20.4.2021

Ngày duyệt bài: 28.4.2021

\section{Nguyễn Quỳnh Anh*, Nguyễn Thu Hà*}

retrospective billing data from hospital discharge records and interviews with 90 liver cancer patients who completed treatment during data collection of the study, from December 2019 to June 2020 at Vietnam National Cancer Hospital. Results and conclusions: During the current treatment, the total direct cost was about 47,305,000 VND with the lowest cost of $12,957,000$ VND and the highest cost of $11,680,000$ VND. For total costs in 2019, the average total direct costs amount to VND 250,857,000 with the lowest cost of VND $31,288,000$ and the highest cost of VND $1,291,727,000$. Among the cost groups, household out-of-pocket expenses accounted for a larger share.

Keywords; Direct treatment costs, liver cancer, Vietnam

\section{I. ĐĂT VẤN ĐỀ}

Ở cả hai giới, ung thư gan đứng hàng đầu với tỷ lệ $15,4 \%$ tổng số mới mắc ung thư, tiếp đến là ung thư phổi, dạ dày, vú, đại trực tràng. Các bệnh phổ biến ở nam giới là ung thư gan, ung thư phổi, ung thư dạ dày, ung thư đại trực tràng và ung thư vòm họng, trong khi các bệnh phổ biến ở nữ giới lần lượt là ung thư gan, ung thư phổi, ung thư vú, ung thư dạ dày và ung thư cổ tử cung. Nghiên cứu gánh nặng bệnh tật tại Việt Nam năm 2017 cũng chỉ ra ung thư phổi, ung thư gan, ung thư đại trực tràng là 3 nhóm bệnh ung thư có gánh nặng hàng đầu trong nhóm bệnh ung thư $(1,2,3)$.

Trong điều kiện nguồn lực hạn chế, chi phí các dịch vụ y tế tăng cao, sự già hóa dân số và nhu câu chăm sóc sức khỏe tăng lên không ngừng, các nhà hoạch định chính sách phải cân 